\title{
Pro-Poor Growth: \\ Illusions of Marriage and Divorce?
}

M.H. Suryanarayana

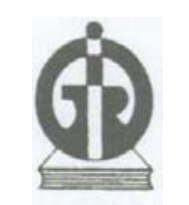

Indira Gandhi Institute of Development Research, Mumbai March 2008

http://www.igidr.ac.in/pdf/publication/WP-2008-006.pdf 


\title{
Pro-Poor Growth: Illusions of Marriage and Divorce? ${ }^{1}$
}

\author{
M.H. Suryanarayana \\ Indira Gandhi Institute of Development Research (IGIDR) \\ General Arun Kumar Vaidya Marg \\ Goregaon (E), Mumbai- 400065, INDIA \\ Email (corresponding author): surya@igidr.ac.in
}

\begin{abstract}
This note seeks to show that the debate on 'Pro-Poor Growth' is sterile and largely academic with few policy insights.
\end{abstract}

Key words: Policy debate, poverty reductionSocio-economic dimension, economic policy, inequality, opportunity cost.

JEL Code(s): I32

${ }^{1}$ Also put up in SSRN. 


\title{
Pro-Poor Growth: Illusions of Marriage and Divorce?
}

\author{
M.H. Suryanarayana
}

The concept of 'Pro-Poor Growth' has received wide currency in recent years. It has been provided with extra legitimacy with the UNDP Human Development Report 2005's special focus on its relevance to policies for poverty reduction. The International Poverty Centre of the UNDP at Brasilia has provided extra space for this debate in its regular publications like the In Focus and the One Pager. The recent issue (\#45) of the One Pager is quite interesting and provocative with its review of the marriage and divorce between alternative definitions of 'Pro-Poor Growth' and approaches to poverty reduction. This note seeks to show that the debate on 'Pro-Poor Growth' is sterile and largely academic with few policy insights for the following reasons:

1. To begin with, it is essentially a debate on ex post characterization of a growth process with reference to distributional outcomes as reflected in estimates of income or consumer expenditure distribution. The final shape and location of distribution of such outcome measures would be determined by factors, many of which are beyond the control of a policy maker. This is particularly so in a modern democratic set up, which an institution like the UNDP advocates for.

2. There is an implicit but very crucial assumption of independence, that is, the growth and inequality-reduction (called Redistribution strategy in India literature) strategies under review are independent of the level of income. This assumption implies that the potential scope for growth/redistribution (inequality-reduction) strategy is independent of the level of income or stage of development. This assumption may not be valid. From a statistical perspective, one would expect a negative covariance between incidence of poverty (head-count measure) and growth (as measured by mean income), which could be either strengthened by favourable distributional changes (involving reduction in inequality called redistribution) or weakened by adverse distributional changes (Suryanarayana, 1980). Of course, one has to discriminate between these two sets of processes, which are qualitatively different, before ranking the states of final outcomes from a welfare perspective. However, as all of us know, the size of the cake itself would sets limits on the scope for generating favourable distributional changes. I illustrate this point using a statistical framework that is, the two-parameter lognormal distribution (Suryanarayana, 1986). The Indian five-year plan exercises on poverty estimation and related issues are generally based on the two-parameter lognormal models. Hence, I use the same framework for purposes of illustration. $^{2}$ As per the lognormal assumption, the per capita consumer expenditure, say $X$, in a given country follows a two-parameter lognormal model with parameters $\theta$ and $\lambda$. Mean value of $X$ and the degree of inequality in the distribution of $\mathrm{X}$ as measured by the Lorenz ratio are monotonic functions of

\footnotetext{
${ }^{2}$ I present this discussion with due acknowledgement of the limitations of the two parameter lognormal model. Thresholds may differ but not the qualitative results.
} 
these two parameters respectively. Further, the measure of absolute poverty $\mathrm{P}^{*}$, defined as the proportion of population having a consumption level below a normatively defined minimum, say $x^{*}$, called poverty line, is given by

$$
P^{*}=\Phi\left[\frac{\ln x^{*}-\theta}{\lambda}\right]
$$

where $\Phi$ is the distribution function. Thus, poverty is a function of the poverty line $\left(\mathrm{x}^{*}\right)$, and parameters $\theta$ and $\lambda$.

How would poverty respond to changes in growth and redistribution? ${ }^{3}$ Partial first- and second-order derivatives of (1) respectively are given by:

$$
\begin{aligned}
& \frac{\delta P^{*}}{\delta \theta}=-\left(\frac{1}{\lambda}\right)\left(\frac{1}{\sqrt{2} \pi}\right) \exp \left[-\frac{1}{2} \frac{\left(\ln x^{*}-\theta\right)^{2}}{\lambda^{2}}\right]<0 \\
& \frac{\delta^{2} P^{*}}{\delta \theta^{2}}=-\left(\frac{1}{\lambda}\right)^{3}\left(\frac{1}{\sqrt{2} \pi}\right)\left(\ln x^{*}-\theta\right) \exp \left[-\frac{1}{2} \frac{\left(\ln x^{*}-\theta\right)^{2}}{\lambda^{2}}\right]
\end{aligned}
$$

Thus, an increase in $\theta$, ceteris paribus, will always cause a reduction in poverty (equation (2)). However, the pace at which poverty decline would depend upon whether the second derivative (equation (3)) is negative, positive or zero. This reduction in poverty will take place at an increasing rate if poverty is less than 50 per cent, occur at a decreasing rate if poverty is greater than 50 per cent, and will be maximum when poverty is equal to 50 per cent. These results are depicted graphically in Figure 1 below.

Fig. 1: Relation between $\theta$ and poverty

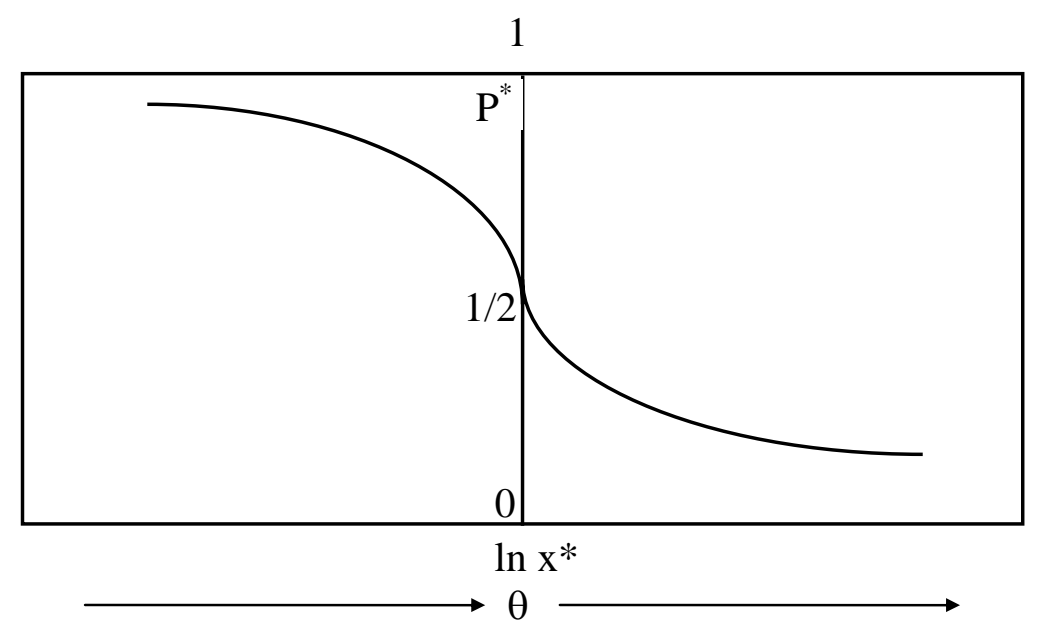

\footnotetext{
${ }^{3}$ This illustration is based on an implicit assumption that the growth and redistribution strategies are separable and could be pursued independently of each other, which is also applicable to the Indian Plan Strategy formulation (see bullet point \# 3 below).
} 
Let us now examine poverty behavior in response to changes in inequality: We have

$$
\frac{\delta P^{*}}{\delta \lambda}=-\left(\frac{1}{\lambda}\right)^{2}\left(\frac{1}{\sqrt{2 \pi}}\right)\left(\ln x^{*}-\theta\right) \exp \left[-\frac{1}{2} \frac{\left(\ln x^{*}-\theta\right)^{2}}{\lambda^{2}}\right]
$$

That is, whether poverty would decline in response to a redistributive effort would depend upon the size of the cake itself. An increase in inequality will increase poverty when it is less than 50 per cent, decrease it when it is greater than 50 per cent; and be neutral when poverty is 50 per cent. Further,

$$
\frac{\delta^{2} P^{*}}{\delta \lambda^{2}}=-\left(\frac{1}{\lambda}\right)^{3}\left(\frac{1}{\sqrt{2 \pi}}\right)\left(\ln x^{*}-\theta\right) \exp \left[-\frac{1}{2} \frac{\left(\ln x^{*}-\theta\right)^{2}}{\lambda^{2}}\right]\left[2-\frac{\left(\ln x^{*}-\theta\right)^{2}}{\lambda^{2}}\right]
$$

Given the lognormal assumption, one can calculate the probability for the event

$$
\frac{\left(\ln x^{*}-\theta\right)^{2}}{\lambda^{2}}<2
$$

for a random X. One can say that whenever the probability is above 8 per cent and less than 92 per cent, this inequality holds. Thus, this inequality holds for most of the developing countries. This would imply that a worsening of distribution will increase poverty at a decreasing rate when poverty is less than 50 per cent, decrease poverty at an increasing rate when it is greater than 50 per cent; and distributional changes will be neutral when poverty is equal to 50 per cent.

The above findings are depicted graphically below in Figure 2.

Fig.2: Relation between inequality and poverty

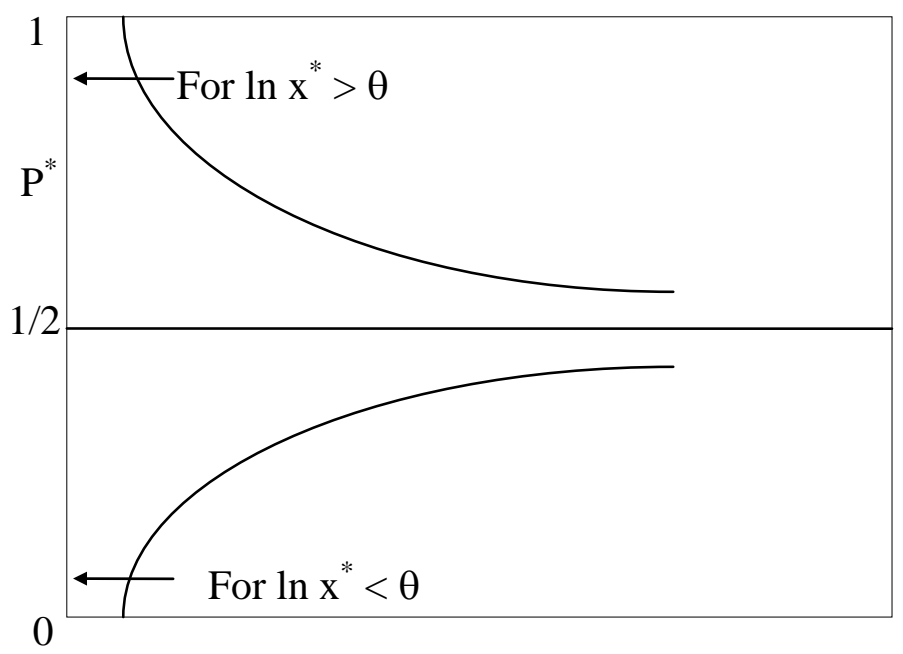

It follows that the precise impact of a growth or reditstribution (reduction in inequality) strategy on poverty reduction depends upon the mean level of income itself i.e. at what stage of development the country is currently placed. While a growth strategy is uniformly poverty reducing, though the pace of 
reduction varies at different stages, a redistribution (reduction in inequality) strategy can reduce poverty only when the size of the cake is large enough so that the poverty level is not acute.

3. The results given above may be illustrated with reference to some historical experience: From a policy formulation perspective, Indian Five Year Plans always laid emphasis on 'Growth with Redistribution' or what one may term it as 'Pro-Poor Growth'. For example, consider the development strategy for the Sixth Five Year Plan (1980-'85). The base year (1979/80) profile of poverty across rural and urban sectors was as follows: incidence of rural poverty was 50.70 per cent and that of urban was 40.31 per cent, that is, virtually half of the population was poor implying limited scope for poverty reduction by brining down inequality (redistribution). However, the Plan sought to reduce poverty during the plan period partly by growth and partly by inequalityreduction. It sought to bring down rural poverty from 50.70 per cent to 40.47 per cent and urban poverty from 40.31 per cent to 33.71 per cent during the Plan period by growth. The Plan provided for a further reduction in both rural and urban poverty ratios to the targeted level of 30 per cent in the terminal year by redistribution or reduction in inequality (Government of India, 1981). The Sixth Plan formulation exercise on poverty reduction called for a reduction in inequality (Lorenz ratio) from 30.53 to 22.16 per cent (a reduction of 27.42 per cent) in rural India and from 33.50 to 30.50 per cent (a reduction of 8.96 per cent) in urban (Suryanarayana, 1983), which was indeed a strategy for 'Aggressive Pro-Poor Growth'. However, even these policy formulation estimates ended up as neat academic exercises with the final outcomes during the Plan period falling far short of the targets based on well-articulated strategies. India could realize the Sixth Five Year Plan (1980-85) target of 30 per cent for poverty not in five years but after pursuing planned pro-poor growth for two and a half decades: incidence of poverty has finally declined to 28.30 per cent in the rural sector and 25.70 per cent in the urban in 2004/05 (Government of India, 2007) thanks largely to growth and not any significant reduction in inequality. Contrary to the Sixth Plan formulation, inequality (Lorenz ratio) in rural consumption distribution has declined marginally from 30.53 to 29.67 per cent while that in the urban one has even increased from 33.50 to 37.24 per cent between 1979/80 and 2004/05.

4. Most important is to note that one is not sure how robust are the statistical estimates of inequality. Hence, comparisons of estimates for only terminal years could be misleading and may not reveal the inter year fluctuations. For instance, estimates of rural and urban poverty ratios for 1993/94 were 37.30 and 32.40 per cent with the associated estimates of inequality (Lorenz ratio) being 25.64 and 33.78 per cent respectively. 


\section{References}

Government of India (1981) A Technical Note on the Sixth Plan of India (1980-85), Planning Commission, New Delhi, India

Government of India (2007): Poverty Estimates for 2004-05, Press Information Bureau, New Delhi, India.

Suryanarayana, M.H. (1980): Growth and Income Distribution in India, MPhil Dissertation submitted to Jawaharlal Nehru University, New Delhi, India

Suryanarayana, M.H. (1986): The Problem of Distribution in India's Development, $\mathrm{PhD}$. Thesis submitted to Indian Statistical Institute, Kolkatta, India.

Suryanarayana, M.H. (1983): 'Treatment of poverty in the Sixth Plan', Artha Vijanana, 25(4), 419-25. 